SUBJECT AREAS:

MATERIALS FOR ENERGY AND CATALYSIS

CHEMICAL ENGINEERING

Received

27 November 2014

Accepted

21 January 2015

Published

13 February 2015

Correspondence and requests for materials should be addressed to K.N. (k.nogita@uq. edu.au)

\section{Evidence of the hydrogen release mechanism in bulk $\mathrm{MgH}_{2}$}

\author{
Kazuhiro Nogita' ', , Xuan Q. Tran' , Tomokazu Yamamoto², Eishi Tanaka², Stuart D. McDonald', \\ Christopher M. Gourlay ${ }^{3}$, Kazuhiro Yasuda ${ }^{2} \&$ Syo Matsumura ${ }^{2}$
}

${ }^{1}$ Nihon Superior Centre for the Manufacture of Electronic Materials, School of Mechanical and Mining Engineering, The University of Queensland, Brisbane, QLD 4072, Australia, ${ }^{2}$ Department of Applied Quantum Physics and Nuclear Engineering and the Ultramicroscopy Research Center, Kyushu University, Fukuoka 819-0395, Japan, ${ }^{3}$ Department of Materials, Imperial College, London. SW7 2AZ. UK.

Hydrogen has the potential to power much of the modern world with only water as a by-product, but storing hydrogen safely and efficiently in solid form such as magnesium hydride remains a major obstacle. A significant challenge has been the difficulty of proving the hydriding/dehydriding mechanisms and, therefore, the mechanisms have long been the subject of debate. Here we use in situ ultra-high voltage transmission electron microscopy (TEM) to directly verify the mechanisms of the hydride decomposition of bulk $\mathrm{MgH}_{2}$ in $\mathrm{Mg}-\mathrm{Ni}$ alloys. We find that the hydrogen release mechanism from bulk $(2 \mu \mathrm{m}) \mathrm{MgH}_{2}$ particles is based on the growth of multiple pre-existing $\mathrm{Mg}$ crystallites within the $\mathrm{MgH}_{2}$ matrix, present due to the difficulty of fully transforming all $\mathrm{Mg}$ during a hydrogenation cycle whereas, in thin samples analogous to nano-powders, dehydriding occurs by a 'shrinking core' mechanism.

$\mathrm{T}$ he storage of hydrogen in solid form as magnesium hydride is a promising technology that is being developed for fuel cells for automotive and stationary applications and to enable safer hydrogen transportation $^{1-3}$. Pure magnesium has a hydrogen carrying capacity of around $7.6 \mathrm{wt} \%$, however, the resulting hydride is relatively stable and the temperature must be increased to $300^{\circ} \mathrm{C}$ at 1 bar $\mathrm{H}_{2}$ for the hydrogen to be released with acceptable release rate with realistic industry use $e^{2}$. Design goals for on-board storage (automotive) aim for a temperature of hydrogen release of between 60 and $120^{\circ} \mathrm{C}^{2}$, however land-based consumer and industrial storage systems do not have such stringent requirements ${ }^{4}$. Much research on $\mathrm{Mg}$-based $\mathrm{H}$-storage materials is based on ball milled nano-scale powders due to their superior $\mathrm{H}$-sorption properties over bulk powders ${ }^{2,5}$. Another approach is to improve the $\mathrm{H}$-sorption properties of bulk powders, for example, by treating liquid Mg-alloys with alkali and alkali-earth metals prior to casting and powder production ${ }^{6}$. A significant challenge in research on both nano-powders and bulk-powders has been the difficulty of proving the hydriding/dehydriding mechanisms and, therefore, the mechanisms have long been the subject of debate ${ }^{1-3}$. Multiple models for the desorption of $\mathrm{MgH}_{2}$ have been developed and these have been placed in several categories including 'shrinking core' models ${ }^{3,7-9}$, 'nucleation and growth' models ${ }^{3,7-9}$, 'multiple step' kinetic models ${ }^{3,7-9}$, 'migration and coalescence' (Greenwood and Speight) model ${ }^{10}$, and an Ostwald ripening model, eg. Ref. 11. Of these models the first two contain largely opposing ideas yet both approaches have been used with some success in the modeling of experimental results from either pressure-composition-temperature (PCT) curves or thermal gravimetric analysis (TGA) and differential thermal analysis (DTA) data ${ }^{3}$. These techniques and others including in-situ heating X-ray diffraction $(\mathrm{XRD})^{2,12}$ and room temperature $\mathrm{TEM}^{13-16}$ do not give direct evidence of the operating mechanisms. Such evidence requires 4-D data, ie., three dimensional observations over time. As such, in-situ temperature controlled TEM observation is an attractive approach for determining the mechanism of hydrogen release. Three groups have reported using in-situ TEM at $200 \mathrm{kV}$ to observe hydrogen desorption ${ }^{15,17,18}$. However, conventional TEM with an accelerating voltage of $200 \mathrm{kV}$ has disadvantages including inelastic incident beam interactions with the samples, and the sample dimensions (typically less than $100 \mathrm{~nm}$ in thickness) make surface effects more prominent ${ }^{19}$. Recently Mooij and $\mathrm{Dam}^{20}$ demonstrated in-situ the two dimensional nucleation and growth of single hydride domains of up to several millimeters in diameter by an optical transmission technique (hydrogenography) for thin Mg film. They found that the nucleation and growth process affects the hysteresis between absorption and desorption.

Here we show the hydrogen release behavior from $\mathrm{MgH}_{2}$ in real-time using in situ ultra-high voltage transmission electron microscopy (TEM), and directly verify the mechanisms of the hydride decomposition of bulk 


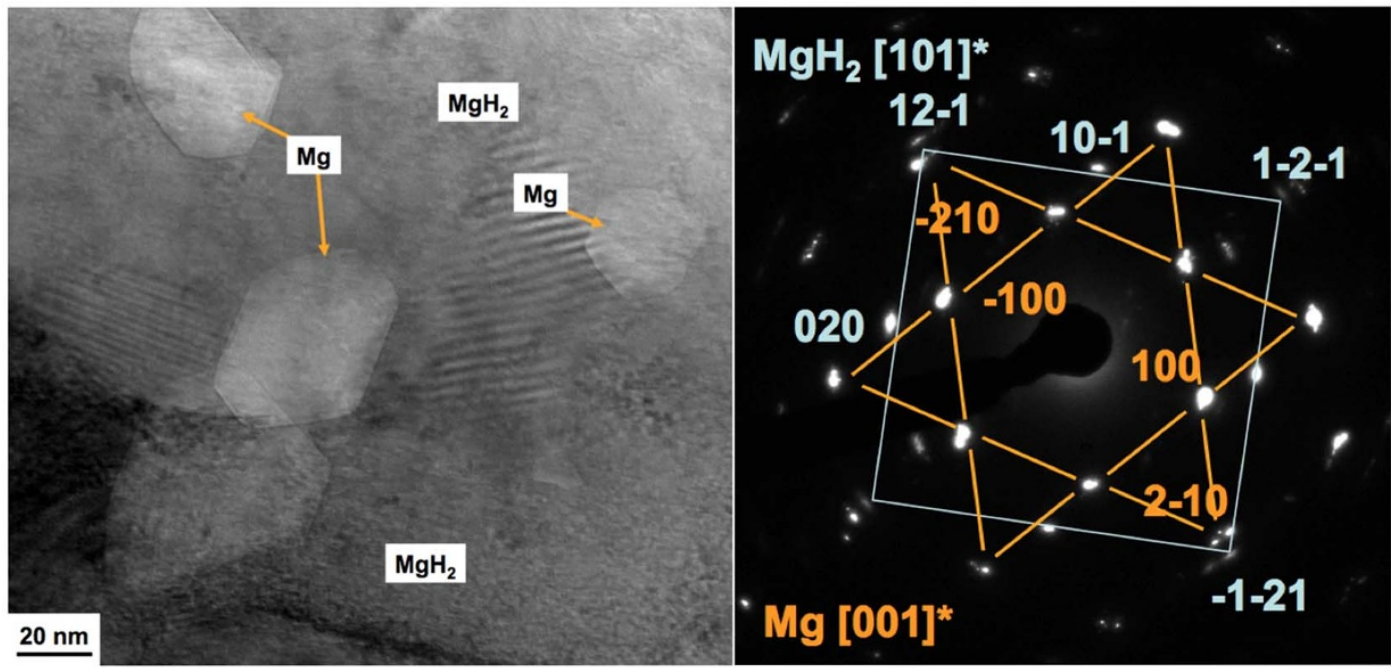

Figure 1 A TEM image and selected area electron diffraction patterns from $\mathrm{Mg}$ and $\mathrm{MgH}_{2}$ phases in a nominally fully hydrogenated sample.

$\mathrm{MgH}_{2}$ in $\mathrm{Mg}-\mathrm{Ni}$ alloys. The ultra-high accelerating voltage $(1,000 \mathrm{kV})$ enables bulk samples a few micrometers in thickness to be studied which minimizes surface effects ${ }^{19}$. The observations are then compared with $\mathrm{MgH}_{2}$ decomposition in thin-samples (tens of $\mathrm{nm}$ ) with length scale analogous to nano-powders.

Figure 1 shows a TEM image and electron diffraction patterns, observed at an acceleration voltage of $300 \mathrm{kV}$, from a $\mathrm{MgH}_{2}$ particle produced by hydriding a $\mathrm{Mg}$-Ni-based $\mathrm{H}$-storage alloy. They show the presence of $\mathrm{MgH}_{2}$ and also $\mathrm{Mg}$ phase as hexagonal shaped $\mathrm{Mg}$ grains of around 30 to $60 \mathrm{~nm}$ size within the $\mathrm{MgH}_{2}$ matrix. From the low indexed electron diffraction patterns from $\mathrm{MgH}_{2}[101]^{*}$ and $\mathrm{Mg}$ $[001]^{*}$ taken from the same selected area diffraction method, diffraction spots of (12-1) from $\mathrm{MgH}_{2}$ and (-210) from $\mathrm{Mg}$ overlap. That means the crystallographic orientation relationships (ORs) between $\mathrm{MgH}_{2}$ and $\mathrm{Mg}$ are $\mathrm{MgH}_{2}[101]^{*} / / \mathrm{Mg}[001]^{*}$ (beam direction) and $\mathrm{MgH}_{2}(12-1) / / \mathrm{Mg}(-210)$ (plane) as well as $\mathrm{MgH}_{2}(101) / / \mathrm{Mg}(002)$ since $\mathrm{MgH}_{2}$ [101] ${ }^{*}$ and $\mathrm{Mg}$ [001] ${ }^{*}$ are perpendicular to $\mathrm{MgH}_{2}(101)$ and $\mathrm{Mg}$ (002). The differences of lattice spacings between $\mathrm{MgH}_{2}$ (121) and $\mathrm{Mg}(-210)$ as well as between $\mathrm{MgH}_{2}(101)$ and $\mathrm{Mg}(002)$ are both about $4 \%$. This crystallographic orientation would represent a low strain energy situation facilitating the hydriding phase transformation from $\mathrm{Mg}$ to $\mathrm{MgH}_{2}$. Also Figure 1 shows the hexagonal facets of the $\mathrm{Mg}$ grains have (100) and (1-10) habit planes within $\mathrm{MgH}_{2}$. Schober et.al. ${ }^{21}$ reported the relationships as $\mathrm{MgH}_{2}[001]^{*} / /$ $\mathrm{Mg}$ [-1-10] * and $\mathrm{MgH}_{2}(200) / / \mathrm{Mg}$ (002), which has a $15.5 \%$ lattice mismatch. Paik et. al. ${ }^{18}$ measured $\mathrm{MgH}_{2}[001]^{*} / / \mathrm{Mg}[-210]^{*}$ and $\mathrm{MgH}_{2}(-110) / / \mathrm{Mg}(002)$, which has a $18.4 \%$ mismatch.

Note that the sample in Figure 1 was nominally fully-hydrided and, therefore, it is necessary to consider why a small volume fraction of nano-sized $\mathrm{Mg}$ grains remained in the $\mathrm{MgH}_{2}$ matrix. In the supporting data, Figure S4 shows scanning electron microscopy (SEM) images prepared from samples quenched at selected times (e.g. 5, 8 and 20 hours) during hydrogen absorption at $340^{\circ} \mathrm{C}$ and $1 \mathrm{MPa}$. A large number of small $\mathrm{MgH}_{2}$ nuclei formed around the $\mathrm{Mg}$ dendrite in the early stages of hydrogenation and grew into the $\mathrm{Mg}$ phase with time. The cracking of the growing $\mathrm{MgH}_{2}$ phase in Figure S4 (b) and (c) is associated with the release of strain energy caused by the large volume change of transformation $\left(30.4 \%\right.$ at $\left.340^{\circ} \mathrm{C}^{22}\right)$. Even after a prolonged period of hydrogenation (e.g. 20 hours in Figure S4 (c)), small islands of the $\mathrm{Mg}$ phase are still retained in the $\mathrm{MgH}_{2}$ matrix. This is likely due to the impingement of growing $\mathrm{MgH}_{2}$ effectively providing a barrier against further hydrogen diffusion because the coefficient of hydrogen diffusion in $\mathrm{MgH}_{2}$ is at least three orders of magnitude less than that in $\mathrm{Mg}^{23}$, and may also be due to strain energy retarding growth as $\mathrm{MgH}_{2}-\mathrm{Mg}$ interfaces grow into the last small $\mathrm{Mg}$ islands surrounded by $\mathrm{MgH}_{2}$ (e.g. Figure 1). Therefore, a key finding in this work is that some $\mathrm{Mg}$ phase is retained after a 'full' hydrogenation cycle. Importantly, it is expected that some $\mathrm{Mg}$ will be retained also at the end of recharging of industrial $\mathrm{H}$-storage systems based on $\mathrm{MgH}_{2}$ bulk powder. This has a significant effect on dehydriding mechanisms as shown in the next sections.

In-situ TEM observations were performed on a $\sim 2 \mu \mathrm{m}$ particle of bulk powder at an acceleration voltage of $1,000 \mathrm{kV}$ with a heating holder and a high resolution video recorder. The temperature at the TEM sample grid over the time of observation is in the supporting data (Figure S1). The average heating rate is approximately $13^{\circ} \mathrm{C} / \mathrm{min}$ from 28 to $455^{\circ} \mathrm{C}$. Concerns that the insulation effects between the TEM sample grid and the specimen may render the measured sample temperature inaccurate can be alleviated by comparing the differential scanning calorimetry (DSC) and TEM data. A comparison of the in-situ hydrogen release observations in the Movie S1, shows the $\mathrm{MgH}_{2}$ to $\mathrm{Mg}$ phase transformation is completed at around $420^{\circ} \mathrm{C}$ and the DSC experiments in Figure S5 show that the hydrogen release peak temperature was $423^{\circ} \mathrm{C}$ at a similar heating rate of $15^{\circ} \mathrm{C} / \mathrm{min}$.

Figure 2(a)-(d) shows selected still frame TEM images taken at the temperatures of (a) $300^{\circ} \mathrm{C}$, (b) $420^{\circ} \mathrm{C}$, (c) $430^{\circ} \mathrm{C}$ and (d) $455^{\circ} \mathrm{C}$ (the observation video is available in Movie S1). Several bright grains were observed in the sample in the low temperature range up to $300^{\circ} \mathrm{C}$, which correspond to Mg grains, similar to those shown in Figure 1. Those $\mathrm{Mg}$ grains subsequently grow and coalesce, with increasing temperature (Figure 2). There are several large $\mathrm{Mg}$ grains at $455^{\circ} \mathrm{C}$, which are clearly shown in the low magnification image in Figure 2(e). These events in the bulk sample correspond well with the DSC shown in the Figure S5 and corresponding Synchrotron $\mathrm{XRD}$ data under air and 0.1 MPa conditions in Figure S3 ${ }^{12}$. This in-situ TEM result is direct evidence that dehydriding of $\sim 2 \mu \mathrm{m}$ bulk $\mathrm{MgH}_{2}$ particles occurs by the growth of multiple pre-existing $\mathrm{Mg}$ grains within a $\mathrm{MgH}_{2}$ matrix.

A volume change (shrinkage) of around $30 \%$ occurs during hydrogen release associated with the phase transformation from $\mathrm{MgH}_{2}$ to $\mathrm{Mg}\left(30.4 \%\right.$ at $340^{\circ} \mathrm{C}$ reported by Ono et $\left.\mathrm{al}^{22}\right)$, and from Figure 2 and Movie S1, we can see some slight shrinkage of the bulk $\mathrm{MgH}_{2}$ particle (around 2 micrometers diameter) and $\mathrm{Mg}$ grains in the bulk $\mathrm{MgH}_{2}$ particle with concave shape at $455^{\circ} \mathrm{C}$ where hydrogen release had stopped. However, there was an absence of any void formation within the bulk particle. It is likely the strain associated with volumetric contraction is accommodated by deformation (including con- 

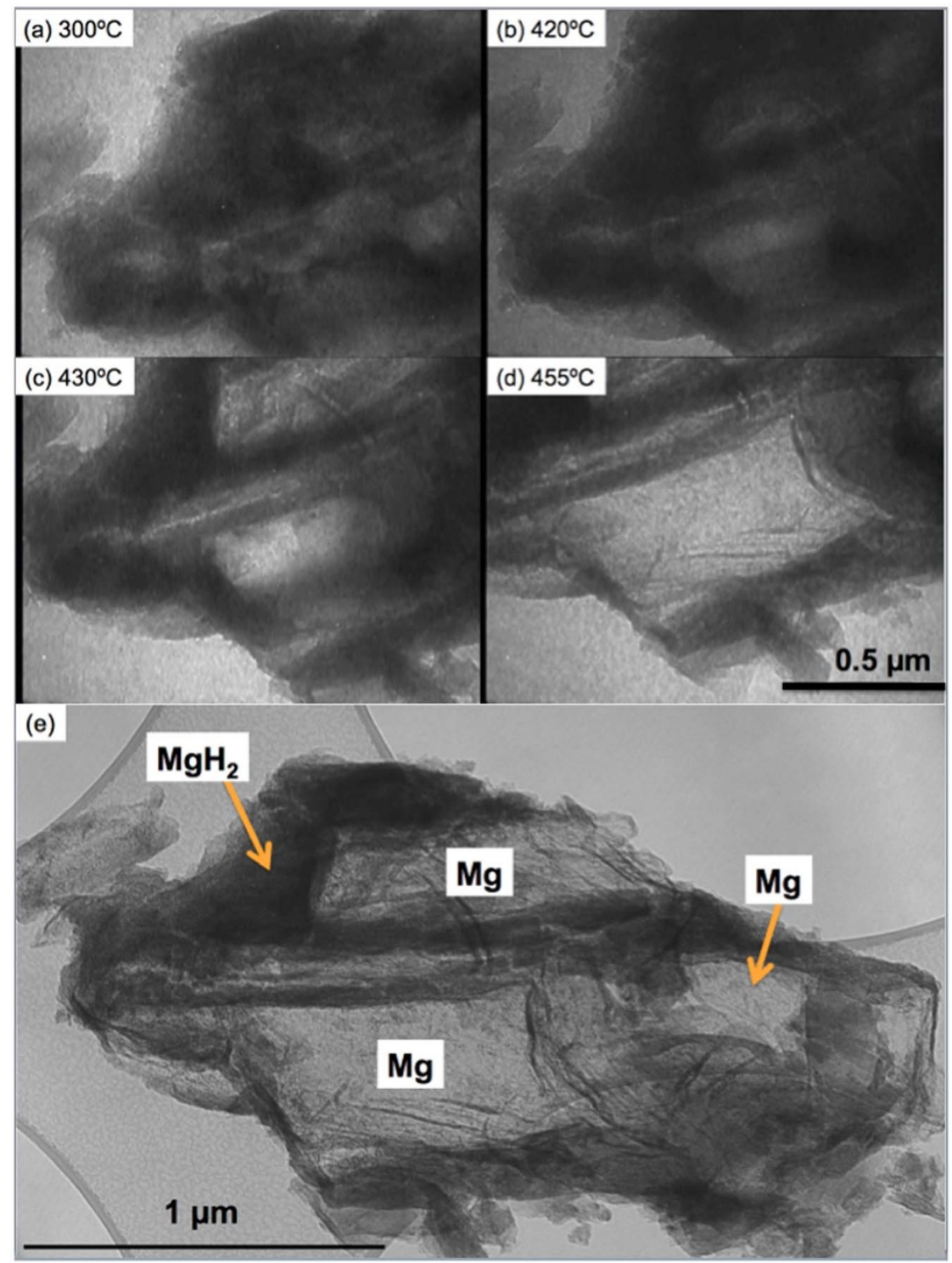

Figure $2 \mid$ Selected still frame TEM images from in-situ video of high voltage $(1,000 \mathrm{kV})$ TEM of a $\sim 2 \mu \mathrm{m}$ bulk $\mathrm{MgH}_{2}$ particle taken at (a) $300^{\circ} \mathrm{C}$, (b) $420^{\circ} \mathrm{C}$, (c) $430^{\circ} \mathrm{C}$ and (d) $455^{\circ} \mathrm{C}$, and (e) a low magnification bright field image of the sample (a single bulk powder particle) at $455^{\circ} \mathrm{C}$.

traction in the transverse direction). At the temperatures involved this deformation appears to be more favourable than the nucleation and growth of porosity, which requires substantial energy.

For comparison, in-situ TEM was performed at $200 \mathrm{kV}$ TEM (Figure 3 and Movie S2). In this case, the thickness in the observation area is a few tens of nanometers as required for imaging at $200 \mathrm{kV}$ and is at the edge of the sample. Figure 3 shows selected still frame TEM images from the in-situ video in Movie S2 taken at the temperatures of (a) $50^{\circ} \mathrm{C}$, (b) $150^{\circ} \mathrm{C}$, (c) $250^{\circ} \mathrm{C}$, and (d) $380^{\circ} \mathrm{C}$. Mg grains form at the thinnest edge of the sample, and progress toward the inside of the $\mathrm{MgH}_{2}$ sample at $\sim 150^{\circ} \mathrm{C}$. This result indicates the mechanism of hydrogen release in this thin section of the sample is quite different from the bulk sample results obtained with highvoltage TEM in Figure 2 and Movie S1. Also, the hydrogen release temperature is much lower than that obtained by high voltage TEM observations (Figure 2 and Movie S1). The influence of conventional $200 \mathrm{kV}$ TEM on dehydriding mechanisms includes, (1) the thin (less than $100 \mathrm{~nm}$ ) sample thickness allowing surface effects to have a disproportionate effect, and (2) the inelastic incident beam interaction with the sample atoms being stronger than at high voltage and, as a result, more pronounced 'electronic excitation' occurs.
From the direct in-situ observations of hydrogen release behavior from the bulk (thick) sample presented in this work, the observations are schematically shown in Figure 4(a), which is closest to the multiple 'nucleation and growth' model ${ }^{3}$, with the important difference that small (tens of $\mathrm{nm}$ ) $\mathrm{Mg}$ grains were pre-existing in the sample (Figure 1) and, therefore, nucleation was not a pre-requisite for the transformation. In this case, the transformation is growth controlled, where hydrogen atoms diffuse from $\mathrm{MgH}_{2}$ with the driving force for grain boundary movement being derived from the free energy difference between atoms in adjacent grains. Also from Figure 2(e), several areas near the grain surface have remained as $\mathrm{MgH}_{2}$ and oxide, indicating that even at $455^{\circ} \mathrm{C}$, some volume still contains hydrogen as the $\mathrm{MgH}_{2}$ phase. The existence of both $\mathrm{Mg}$ and $\mathrm{MgH}_{2}$ phases after both charging and discharging is likely to play an important role in hydriding/dehydriding kinetics of bulk powder. The effect of pre-existing $\mathrm{Mg}$ grains on the dehydrogenation of $\mathrm{MgH}_{2}$ was reported by Tanniru et. al. ${ }^{24}$, using scanning electron microscopy. They concluded that the nucleation barrier for hexagonal close-packed $\mathrm{Mg}$ plays an important role in establishing the hydrogen release temperature. When the magnesium powders are hydrogenated such that the surface is completely covered by the 


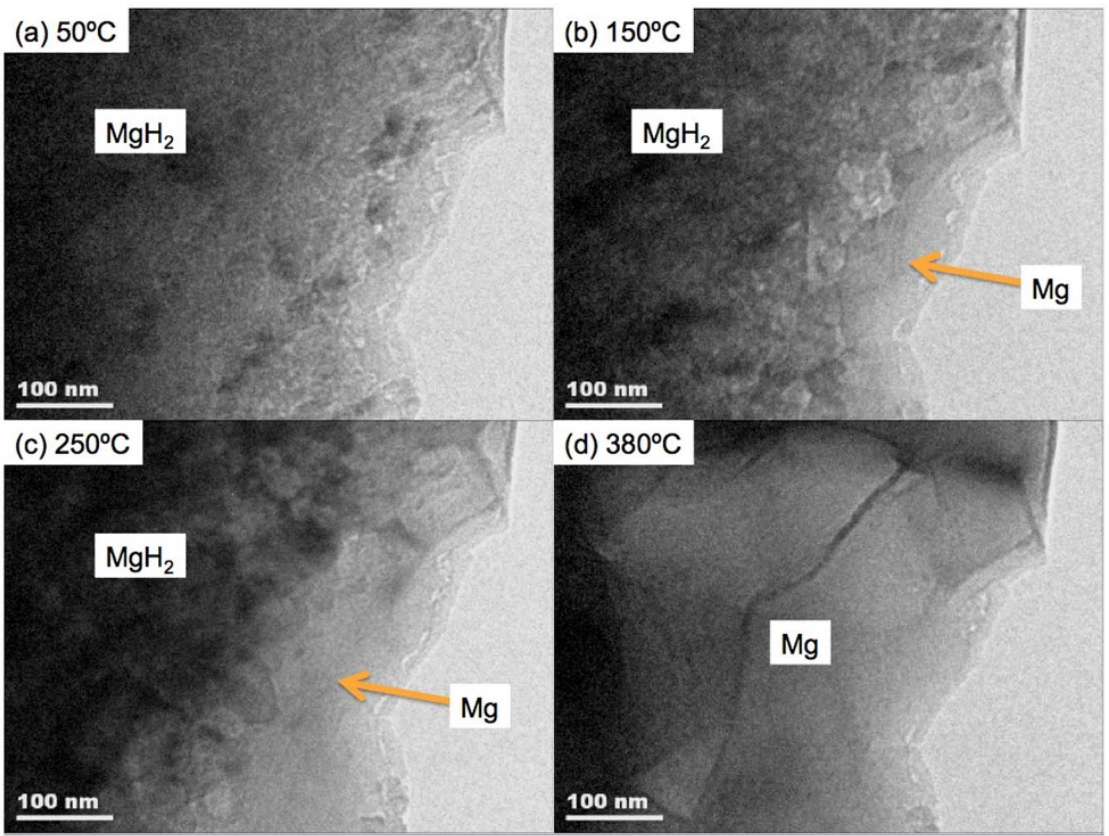

Figure 3 Selected still frame TEM images from in-situ video of conventional (200 kV) TEM through a thinned region (a few tens of $\mathrm{nm})$ of a $\mathrm{MgH}_{2}$ particle taken at (a) $50^{\circ} \mathrm{C}$, (b) $150^{\circ} \mathrm{C}$, (c) $250^{\circ} \mathrm{C}$, and (d) $380^{\circ} \mathrm{C}$.

hydride phase, the desorption temperature is found to be high, owing to the energy required for the nucleation of the $\mathrm{Mg}$ on the surface. Antisari et. al. ${ }^{25}$ have confirmed the difficulty of $\mathrm{Mg}$ nucleation in $\mathrm{MgH}_{2}$, and the presence of some retained $\mathrm{Mg}$ phase is likely to accelerate dehydriding kinetics. If there were no pre-existing $\mathrm{Mg}$ grains, surface nucleation would be easier than nucleation within the volume due to the volume change. However, in the presence of pre-existing $\mathrm{Mg}$ grains within the volume, growth from within is more favourable than nucleation and growth from the surface.

The thin sample (tens of nm thick) studied by conventional TEM at $200 \mathrm{kV}$ in Figure 3 and Figure 4(b) may reflect the behavior of fine

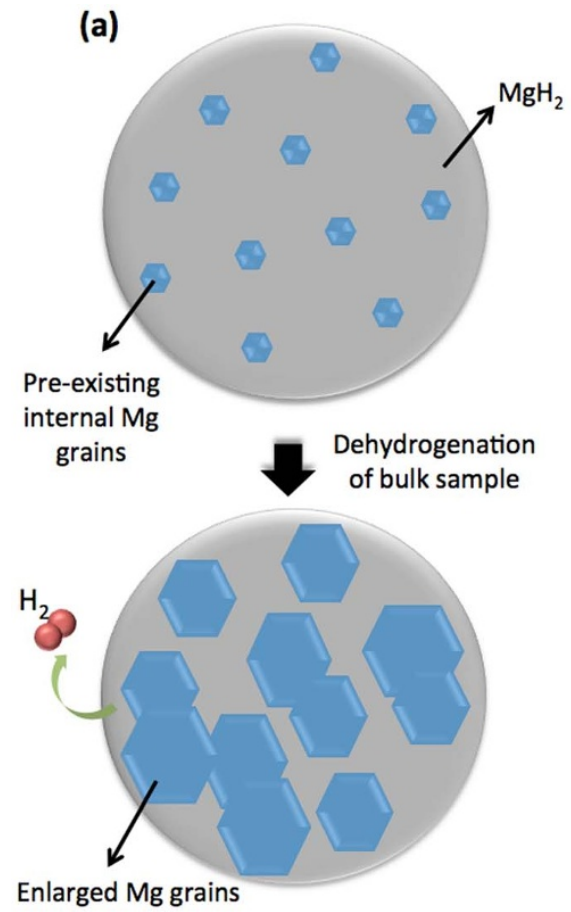

nano-powders as well as election beam heating effect due to the inelastic incident beam interactions with the samples ${ }^{19}$. In this case, the formation of $\mathrm{Mg}$ at the sample edge followed by growth into the $\mathrm{MgH}_{2}$ is consistent with 'shrinking core' models, where nucleation and growth of $\mathrm{Mg}$ phase happen from the edge/surface of the sample. Based on 'shrinking core' models, Ouyang et. al. ${ }^{26}$ found the hydriding/dehydriding process in nano-grained (around $30 \mathrm{~nm}$ in diameter) of $\mathrm{Mg}$ is catalyzed by the combination of in situ formed extremely fine $\mathrm{CeH}_{2} / \mathrm{CeH}_{2.73}$ and $\mathrm{Ni}$ to $\mathrm{Mg} / \mathrm{MgH}_{2}$. The experiments performed were not isothermal and did not enable a comparison of the kinetics of hydrogen transportation through the surrounding

(b)
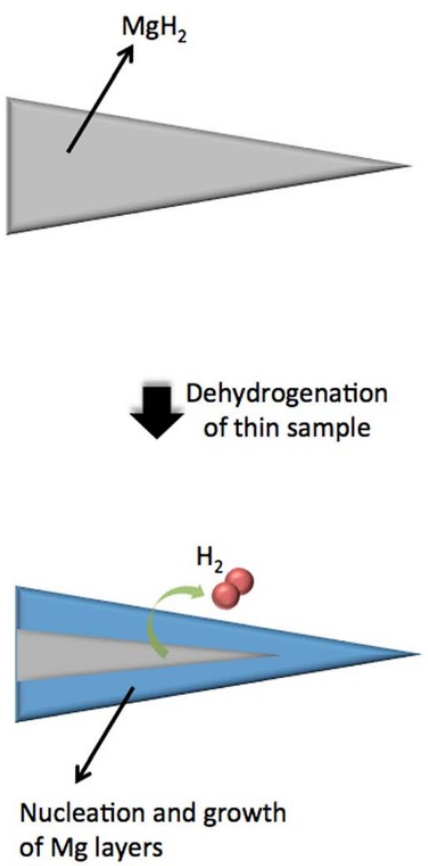

Figure 4 | Schematic hydrogen release mechanisms from a $\mathrm{MgH}_{2}$ grain: (a) multiple 'nucleation and growth' model for bulk $\mathrm{MgH}_{2}$ grains and (b) 'shrinking core' model for thin $\mathrm{MgH}_{2}$ TEM samples. 
$\mathrm{MgH}_{2}$ phase between the thin and bulk samples. While the overall thickness of the thin samples will be the dominant geometric factor influencing the desorption rate the spatial distribution of any preexisting Mg nuclei and in particular the distance of these nuclei from the free surface will play an important role in determining the desorption rate of the bulk samples.

From in-situ TEM imaging, we conclude that the hydrogen release mechanism from bulk $(2 \mu \mathrm{m}) \mathrm{MgH}_{2}$ particles is based on the growth of multiple pre-existing $\mathrm{Mg}$ grains (crystallites within the $\mathrm{MgH}_{2}$ matrix) present due to the difficulty of fully transforming all $\mathrm{Mg}$ during a hydrogenation cycle whereas, in thin samples analogous to nano-powders, dehydriding occurs by a 'shrinking core' mechanism.

\section{Methods}

$\mathbf{M g H}_{2}$ sample preparation. To prepare samples for hydrogen absorption they were machined to fine chips in air using a drill press. The unreacted chips were of the order of $0.1 \mathrm{~mm}$ thick and a few $\mathrm{mm}$ in length. Hydrogen sorption was conducted using an automated gravimetric testing apparatus PCTM-5000A (Technosystem Ltd., Japan $)^{27}$ using laboratory grade high purity $\mathrm{H}_{2}$ gas (99.98\% purity). The apparatus levitates approximately one gram of the sample material and directly records the weight change using a balance. The details of this machine are described elsewhere $e^{6,27}$. The samples were 'hydrided', under conditions of $2 \mathrm{MPa}, 350^{\circ} \mathrm{C}$ for 20 hours. During hydriding, $\mathrm{MgH}_{2}$ and $\mathrm{Mg}_{2} \mathrm{NiH}_{4}$ formed and significant cracking occurred, reducing the particle size to a few $\mu \mathrm{m}$. All TEM results presented in the main paper are from powder particles containing $\mathrm{MgH}_{2}$ and no discernable $\mathrm{Mg}_{2} \mathrm{NiH}_{4}$.

Sample preparation for high voltage $(1,000 \mathrm{kV})$ TEM involved selecting single particles of $\mathrm{MgH}_{2}$ from the reaction product and loading them on a temperature controlled TEM sample holder with a $3 \mathrm{~mm}$ diameter grid for high temperature use. Note that particles were examined without any further mechanical/chemical preparations which would be difficult using conventional TEM with $200 \mathrm{kV}$.

Conventional $200 \mathrm{kV}$ TEM was also performed for comparison with the $1,000 \mathrm{kV}$ experiments and to explore the influence of sample thickness and beam heating on dehydriding mechanisms. To produce thin samples for conventional TEM, $\mathrm{MgH}_{2}$ particles were selected from the hydride powder and fractured in an agate mortar producing fragments with edges a few tens of nanometers in thickness.

TEM observations. For the detailed crystallography of $\mathrm{Mg}$ and $\mathrm{MgH}_{2}$ and their relative orientation relationships, a transmission electron microscopy (TEM), JEM3200FSK (JEOL, Japan) at acceleration voltage of $300 \mathrm{kV}$ with an Omega filter was used. In-situ TEM observations were performed using a JEM-1000 (JEOL, Japan) at an acceleration voltage of $1,000 \mathrm{kV}$ with an EM-HSTH (JEOL, Japan) heating holder and high resolution video recorder.

For comparison with conventional in-situ TEM observations, we used a JEM2100 HCLM (JEOL, Japan) at an acceleration voltage of $200 \mathrm{kV}$ with a Model 652 (GATAN, U.S.A.) double tilt heating holder.

1. Reilly, J. J. \& R, H. Wiswall, J. The Reaction of hydrogen with alloys of magnesium and nickel and the formation of $\mathrm{Mg}_{2} \mathrm{NiH}_{4}$. Inorg. Chem. 7, 2254-2256 (1968).

2. Sakintuna, B., Lamari-Darkrim, F. \& Hirscher, M. Metal hydride materials for solid hydrogen storage: A review. Int. J. Hydrogen Energy 32, 1121-1140 (2007).

3. Stepura, G., Rosenband, V. \& Gany, A. A model for the decomposition of titanium hydride and magnesium hydride. J. Alloys Compd. 513, 159-164 (2012).

4. Moroz, S. et al. Systems based on hypo-eutectic $\mathrm{Mg}-\mathrm{Mg}_{2} \mathrm{Ni}$ alloys for medium to large scale hydrogen storage and delivery. J. Alloys Compd. 580, S329-S332 (2013).

5. Dornheim, M., Eigen, N., Barkhordarian, G., Klassen, T. \& Bormann, R. Tailoring hydrogen storage materials towards application. Adv. Eng. Mater. 8, 377-385 (2006).

6. Nogita, K. et al. Engineering the $\mathrm{Mg}-\mathrm{Mg}_{2} \mathrm{Ni}$ eutectic transformation to produce improved hydrogen storage alloys. Int. J. Hydrogen Energy 34, 7686-7691 (2009)

7. Wang, P., Wang, A. M., Wang, Y. L., Zhang, H. F. \& Hu, Z. Q. Decomposition behavior of $\mathrm{MgH}_{2}$ prepared by reaction ball-milling. Scripta Mater. 43, 83-87 (2000).

8. Castro, F. J. \& Meyer, G. Thermal desorption spectroscopy (TDS) method for hydrogen desorption characterization (I): theoretical aspects. J. Alloys Compd. 330-332, 59-63 (2002)

9. Gabis, I., Evard, E., Voyt, A., Chernov, I. \& Zaika, Y. Kinetics of decomposition of erbium hydride. J. Alloys Compd. 356-357, 353-357 (2003).

10. Greenwood, G. W. \& Speight, M. V. Grain boundary mobility and its effects in materials containing inert gases. Philosophical Magazine 9, 683-689 (1964).

11. Goodhew, P. J. Cavity growth mechanism maps. Scripta Mater. 18, 1069-1073 (1984).

12. Nogita, K., McDonald, S. D., Duguid, A., Tsubota, M. \& Gu, Q. F. Hydrogen desorption of $\mathrm{Mg}-\mathrm{Mg}_{2} \mathrm{Ni}$ hypo-eutectic alloys in Air, $\mathrm{Ar}, \mathrm{CO}_{2}, \mathrm{~N}_{2}$ and $\mathrm{H}_{2}$. J. Alloys Compd. 580, S140-S143 (2013).
13. Danaie, M. \& Mitlin, D. TEM analysis and sorption properties of high-energy milled $\mathrm{MgH}_{2}$ powders. J. Alloys Compd. 476, 590-598 (2009).

14. Tanaka, K., Miwa, T., Sasaki, K. \& Kuroda, K. TEM studies of nanostructure in melt-spun $\mathrm{Mg}-\mathrm{Ni}$-La alloy manifesting enhanced hydrogen desorbing kinetics. J. Alloys Compd. 478, 308-316 (2009).

15. Isobe, S. et al. Study on reaction mechanism of dehydrogenation of magnesium hydride by in situ transmission electron microscopy. Appl. Phys. Lett. 96, 223109 223101-223103 (2010).

16. Fujii, H. et al. Remarkable hydrogen storage, structural and optical properties in multi-layered Pd/Mg thin films. Materials Transactions 43, 2721-2727 (2002).

17. Danaie, M., Tao, S. X., Kalisvaart, P. \& Mitlin, D. Analysis of deformation twins and the partially dehydrogenated microstructure in nanocrystalline magnesium hydride $\left(\mathrm{MgH}_{2}\right)$ powder. Acta Mater. 58, 3162-3172 (2010).

18. Paik, B. et al. $\mathrm{MgH}_{2}-\mathrm{Mg}$ phase transformation driven by a high-energy electron beam: An in situ transmission electron microscopy study. Philos. Mag. Lett. 90, 1-7 (2010).

19. Tanaka, M. et al. Sequential multiplication of dislocation sources along a crack front revealed by high-voltage electron microscopy and tomography. J. Mater. Res. 26, 508-513 (2011).

20. Mooij, L. \& Dam, B. Hysteresis and the role of nucleation and growth in the hydrogenation of Mg nanolayers. PCCP 15, 2782-2792 (2013).

21. Schober, T. The magnesium-hydrogen system: Transmission electron microscopy. Metall. Trans. A 12, 951-957 (1981).

22. Ono, S. et al. Phase transformation and thermal expansion of $\mathrm{Mg}-\mathrm{Ni}$ alloys in a hydrogen atmosphere. Journal of the Less Common Metals 88, 57-61 (1982).

23. Cermák, J. \& Král, L. Hydrogen diffusion in $\mathrm{Mg}-\mathrm{H}$ and $\mathrm{Mg}-\mathrm{Ni}-\mathrm{H}$ alloys. Acto Mater. 56, 2677-2686 (2008)

24. Tanniru, M., Tien, H.-Y. \& Ebrahimi, F. Study of the dehydrogenation behavior of magnesium hydride. Scripta Mater. 63, 58-60 (2010).

25. Antisari, M. V. et al. Scanning electron microscopy of partially de-hydrogenated $\mathrm{MgH}_{2}$ powders. Intermetallics 17, 596-602 (2009).

26. Ouyang, L. Z. et al. Enhanced hydrogen storage kinetics and stability by synergistic effects of in situ formed $\mathrm{CeH}_{2.73}$ and $\mathrm{Ni}$ in $\mathrm{CeH}_{2.73}-\mathrm{MgH}_{2}-\mathrm{Ni}$ nanocomposites. The Journal of Physical Chemistry C 118, 7808-7820 (2014).

27. Yamada, A. \& Funatsu, T. Measuring system for absorbed hydrogen using magnetic levitation system. Fuel Cell (Japan) 4, 25-29 (2004).

\section{Acknowledgments}

This research was supported by a JSPS Fellowship for Research in Japan (S11730), a Kyushu University Short-term Young Scholar Exchange Program, a Smart Futures Fellowship from the Queensland Government, Australia and by Hydrexia Pty. Ltd. We thank Mr. Takahiro Nogita at Film School, Griffith University for video editing, Dr. Qinfen Gu at the Australian Synchrotron for assistance with XRD experiments (AS093/PD1726, AS102/PD/QLD/ FI2488 and AS131/PD5782), and the ANFF-Q and CMM at the University of Queensland for use of the DSC and SEM facilities.

\section{Author contributions}

K.N. contributed to the planning of all experiments, participating TEM and Synchrotron XRD experiments and writing the article. X.Q.T. contributed to the discussion and conducted DSC and SEM experiments and Synchrotron XRD data analysis. T.Y. contributed to the discussion and TEM experiments and analysis. E.T. contributed to the discussion and TEM experiments and analysis. S.D.M. contributed to the planning of all experiments, discussion, and writing the article. C.M.G. contributed to the interpretation, discussions, and writing the article. K.Y. contributed to the planning of all experiments, TEM data analysis and discussion. S.M. contributed to the planning of all experiments, TEM data analysis, discussion, and writing the article.

\section{Additional information}

Supplementary information accompanies this paper at http://www.nature.com/ scientificreports

Competing financial interests: K.N. holds a patent on modification of hypoeutectic $\mathrm{Mg}-\mathrm{Ni}$ alloys with alkali and alkali-earth metals (K. Nogita and A. K. Dahle, "Magnesium Alloys for Hydrogen Storage”, International Patent Application No: WO 2006/060851, 2/12/2005) which resulted in a spin-off company Hydrexia Pty. Ltd. which is working to build a commercial H-storage system from this technology. This letter is about the fundamental mechanisms of dehydriding of $\mathrm{MgH}_{2}$ and is not related to the claims of the patent and has no direct financial implications on the work of Hydrexia Pty. Ltd. K.N. also supervises an ongoing research project at the University of Queensland funded by Hydrexia Pty. Ltd.

How to cite this article: Nogita, K. et al. Evidence of the hydrogen release mechanism in bulk $\mathrm{MgH}_{2}$. Sci. Rep. 5, 8450; DOI:10.1038/srep08450 (2015).

This work is licensed under a Creative Commons Attribution 4.0 International License. The images or other third party material in this article are included in the article's Creative Commons license, unless indicated otherwise in the credit line; if the material is not included under the Creative Commons license, users will need to obtain permission from the license holder in order to reproduce the material. To view a copy of this license, visit http://creativecommons.org/licenses/by/4.0/ 